\title{
Off-the-shelf Non-Intrusive Load Monitoring Devices Utilised in a Low Activity Detection Service
}

\author{
Tim D. Hunt, Dileep Rajendran, Mark Nikora, Susan Bennett, Andy Fendall \\ Centre for Business Information Technology and Enterprise. Waikato Institute of Technology \\ Hamilton, 3240, New Zealand \\ tim.hunt@wintec.ac.nz
}

\begin{abstract}
There is a growing awareness for the need to provide low cost solutions for the care of the elderly and in particular to allow them to keep living independent lives. In parallel to this, there have also been significant advances in a number of technical areas including 1) monitoring electricity consumption for the purpose of reducing power costs, 2) non-intrusive load monitoring (NILM), 3) using sensors to determine activities of daily living and 4) cloud computing. The purpose of this work was to demonstrate that it is possible to use a readily available consumer off the shelf electricity monitor to provide a low intrusive activity monitor for older persons. This work uses the Design Science Research Methodology and builds on the results of our previous work that used raw electricity usage data. In this work we are trailing the use of a meter that uses NILM to identify individual appliances in the home. The information on appliance use was analysed by a cloud base program and alerts were sent to the carer when lower than expected activity was detected. Participants both in this work and those reported in the literature have mentioned the annoyance of having multiple sensors in a home, especially if they emit either constant or flashing light. In contrast, NILM allows the use of multiple electrical appliances to be monitored without the need for a large number of sensors to be deployed - just one sensor at the meter or fuse board. The confluence of a number of technologies has enabled the creation of a low intrusive and low cost monitoring system to have become a reality. The initial trial of the system has been shown to be a most reliable alternative to a system built on multiple sensors. Based on previous work that involved the deployment of multiple sensors, the new system is expected to be more acceptable as it has the desired attribute of becoming invisible to the user.
\end{abstract}

Keywords: activities of daily living, non-intrusive load monitoring, elderly, cloud. 


\section{Resumen}

Existe una creciente concienciación respecto a la necesidad de proporcionar soluciones de bajo coste para el cuidado de la tercera edad y, en particular, para permitirles seguir manteniendo una vida independiente. De forma paralela, se han producido también importantes avances en diversos ámbitos técnicos, entre los que se incluyen: 1) monitorización del consumo de electricidad con la finalidad de reducir los costes de energía; 2) monitorización no invasiva de la carga (NILM, por sus siglas en inglés); 3) uso de sensores para determinar actividades de la vida diaria, y 4) computación en nube. La finalidad de este trabajo es demostrar que es posible emplear un dispositivo de control fácilmente disponible a la venta para el consumidor, con el fin de proporcionar una monitorización poco invasiva de la actividad de las personas mayores. Este trabajo emplea la metodología de investigación científica sobre el diseño y parte de los resultados de nuestro trabajo anterior, en el que se emplearon los datos brutos sobre el uso eléctrico. En este trabajo realizamos un seguimiento del uso de un contador que emplea la NILM para identificar electrodomésticos individuales en el hogar. Se analizó la información sobre el uso de electrodomésticos mediante un programa base de computación en nube y se enviaron alertas al cuidador cuando se detectó una actividad menor de la esperada. Los participantes en este trabajo y en otros que constan en el corpus científico han mencionado la molestia de mantener múltiples sensores en el hogar, especialmente si emiten una luz constante o intermitente. Por el contrario, la NILM permite supervisar el uso de múltiples electrodomésticos sin necesidad de desplegar un gran número de sensores: basta con un sensor colocado en el contador o en el cuadro de fusibles. La confluencia de diversas tecnologías ha permitido hacer realidad la creación de un sistema de monitorización poco intrusivo y de bajo coste. La prueba inicial del sistema ha demostrado ser una alternativa totalmente segura al sistema basado en múltiples sensores. A partir del trabajo previo que implicó el despliegue de múltiples sensores, se espera que el nuevo sistema sea más aceptable, pues tiene la característica positiva de hacerse invisible para el usuario.

Palabras clave: actividades de la vida diaria, monitorización no invasiva de la carga, tercera edad, nube.

\section{Introduction}

The search to find socially acceptable methods of using technology to assist the lives of older people has been ongoing for a number of years. One aspect of this is to provide an acceptable method of monitoring that does not intrude into people's privacy. This objective is probably not completely achievable and so we are left with finding a compromise between helping and interfering. Many studies have taken the technology driven approach that seems to ignore not just the actual privacy of the person, but also the perceived privacy. In some studies living spaces have been saturated with numerous sensors (Monekosso \& Remagnino, 2007; Chen, 2010; Cook $\&$ Holder, 2011), and even if the data collected is not continually monitored, it can still leave the person feeling that they have lost their privacy.

One method of monitoring that shows promise for being low intrusion is the use of electricity consumption data (Clement, Ploennigs, \& Kabitzsch, 2012). A considerable amount of information can be gathered from looking at which appliances are used. The advantage of this technique is that it does not require sensors such as cameras or motion detectors that are usually deemed to be intrusive. Previous work by the authors (Hunt, Rajendran, Bennett, \& Fendall, 2014) used analysis of electricity consumption to create basic alerts when expected activity did not occur. This previous investigation was the starting point for this current study and will be briefly discussed later.

Using the total electricity consumption of a home can give a basic idea of whether the occupant is using appliances, however, this is not as useful as knowing what appliances are actually used. This is especially important if the home contains appliances that automatically switch on and off such as an air conditioning unit or a hot water heater. The situation can be improved by monitoring each wiring circuit separately, or for more precise information, by monitoring at the individual appliance.

However, monitoring at each individual appliance increases the complexity of the system with each additional monitoring device being an extra cost, source of failure and inconvenience to the per- 
son. An area of research called Non-Intrusive Load Monitoring (NILM) that starts with the total consumption for a home and separates out the switching on and off of individual appliances offers an elegant solution: with only one physical monitoring point yet giving individual appliance data (Farinaccio \& Zmeureanu, 1999; Hart, 1992; Berges, Goldman, Matthews, Soibelman, \& Anderson, 2011; Chahine, et al., 2011). A number of such devices that use NILM have become available to the consumer, primarily for the purpose of keeping track of electricity costs of appliances (smappee, 2015; Navetas energy management, 2015; The energy detective, 2015). This offers the possibility of using these devices to determine some of the activities of daily living (Lawton \& Brody, 1969) via the appliance use data.

\section{Previous Work}

This work builds on our previous study that used the electricity meter from Current Cost (Current cost, 2015). The setup consisted of monitoring individual circuits (such as the bedroom) as well as at individual appliances of interest such as the television and microwave oven. The data was sent to the Current Cost server where it was analysed by our own cloud based program running on Google App Engine (GAE) (Google, 2015). Basic logic was implemented that allowed the raising of an alert via email, text message or voice call if a set threshold of current was not reached during a specific time period. The system allowed the person being monitored to be contacted before their carer, thus giving them the chance to acknowledge to the system that they were okay, and so avoiding the system informing the carer when there was no need to. This feature was seen as an important feature to empower the user and help reduce the sense of being watched.

\section{Method}

We frame our research within the Design Science Research Methodology (DSRM) (Peffers, Tuunanen,
Rothenberger, \& Chatterjee, 2007) as it is suitable for the creation of artefacts, especially when an iterative process is used to build on previous results such as this.

\section{Evaluation of previous work}

Consistent with the DSRM, we start this work with an evaluation of the previous trial which came to an end after approximately one year. Although we intended for the trial to be ongoing, both of the participants chose to end the trial. Reasons given for wanting to end the trial included:

- Not liking the fact that a light flashed on the monitor every time they entered the room.

- Concern over the amount of electricity being used by the monitor.

- A crackling noise from one of the monitors.

- Tripping of a power board.

- A possible reason for the problems they were having with their Internet connection.

These issues were very real for the participants and no attempt was made to persuade them otherwise. What we learnt was that we really need to make the technology invisible to the person being monitored. It is also worth noting that the common trouble shooting practice is to do exactly what the participants did do and suspect, and remove any extra sources of fault when something went wrong -such as the Internet connection.

\section{Implementing a NILM based meter}

NILM has been implemented in the consumer energy monitoring device from smappee and can automatically identify appliances in a home from a single current measurement point. The smappee device offers an Application Programming Interface (API) to their server allowing third party developers to access the appliance usage information. We have modified our GAE server application to collect this 
information and again use basic logic to determine if there is a need to raise an alarm.

Figure 1 shows a picture of the smappee device installed at the fuse board of a home. This is the only piece of hardware required, but it does rely on the home having a Wi-Fi based Internet connection. Unlike the Current Cost device that was battery powered, the smappee device requires a mains power supply. The device has a relatively straight forward setup procedure but the physical installation needs to be done by a qualified electrician and software configuration by someone with basic computer skills.

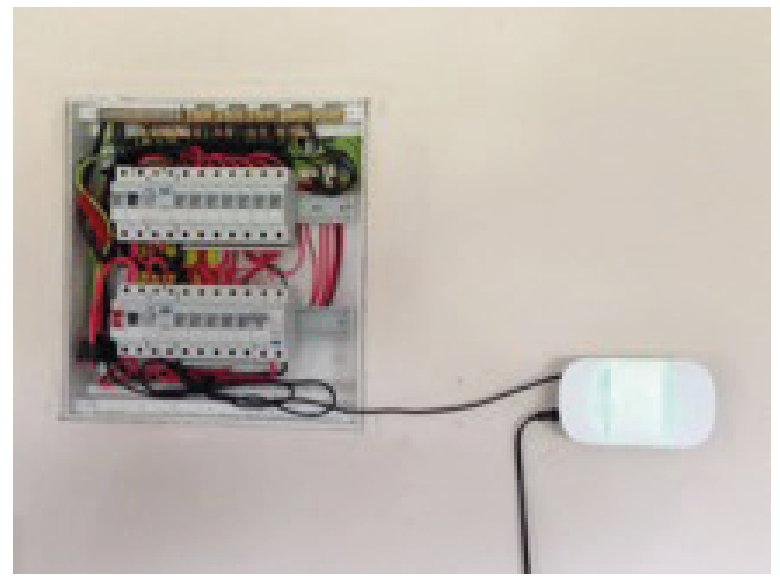

Figure 1. The smappee meter (white box with green lights) located at the fuse board. The actual current sensor is located out of sight behind the fuse panel

\section{Which appliances are useful?}

We sought to implement a system that required as little setup as possible. So instead of requiring the user to decide which appliances would be worth monitoring, we automatically assessed each appliance and if the number of times it turned on and off did not change significantly over each 24 -hour period, we assumed that it was likely to be turning on automatically and so would not give any useful information about the wellness of the occupant. A percentage difference of greater than $80 \%$ between the busiest hour and the quietest hour seemed to give good differentiation as given by: if

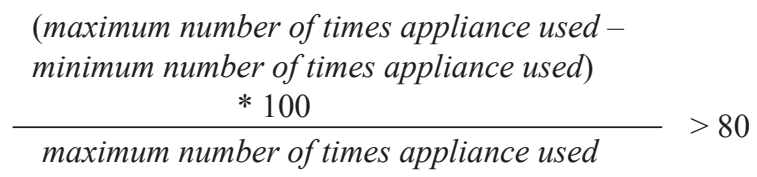

then the appliance is useful. This analysis was repeated daily to allow for changing patterns of behaviour and changes of appliances being used.

An $80 \%$ level of difference was able to label the refrigerator as not being a useful appliance. With all the appliances appropriately labelled, analysis was then performed to create a basic alert that identified 'low activity days'. The day of the week was taken into account and the number of events of all useful appliances was compared with a 4-week average for the same day of the week. The carer can choose the level of sensitivity for alerts being created from a change (from normal) of either $25 \%, 50 \%$ or $75 \%$, where $25 \%$ is going to have the most false positive alerts.

The carer can set the time of day for checking the number of events. This enables an alert to be sent after a particular time of day, for example, after breakfast. If an alert has been set for say 11 a.m., then the system compares the number of events for the day up to $11 \mathrm{a} . \mathrm{m}$. with other days also up to $11 \mathrm{a} . \mathrm{m}$.

\section{Integration into existing system}

The existing Java (Oracle, 2015) based program running on GAE was modified to incorporate the new features. The user interface was modified to allow the carer to enter configuration information to access the smappee server and set up the alerts as described above. The rest of the code was largely left unchanged, which greatly reduced the time required to implement and test the new features based on the smappee meter. This allowed the original code that integrated with the Twilio (Twilio, 2015) server to continue to be used to send text or voice messages as before.

\section{Results and future work}

The smappee device has so far only been tested in a trial home rather than in homes of older people. The trial home had a family of four rather than the intended one person occupancy. The trial was able 
to ascertain the technology did mostly function as designed with alerts being raised when activity was low. One concern with the smappee device is that it lost connection to the server on two occasions in the 4-month period and had to be powered off and on to reconnect. This seems to be a known issue and will hopefully be resolved by smappee in future versions of their device. As it stands, it is going to be impractical to have to manually power off/on the device, but perhaps a device to automatically do this could be installed.

One of the reasons that the smappee device has not yet been installed in participants homes is the need to have a mains power supply near the switch board installation location. This was not required for the previous meter that was battery powered and we are waiting for the necessary work to be done. We are also looking at installing the devices in a number of homes situated in a community location with the intention that a single Internet access point is used by all the meters. This will avoid the issue of finding participants with Internet access and besides it will not rely on the need to configure different Wi-Fi access passwords for each smappee meter. In the previous setup we used a mobile phone network to connect the Internet router to the Internet service provider as no phone line was available. To avoid unexpected network costs, the system was on a prepay arrangement and this caused some instances of connection interruption. We are intending to have a fixed phone line for the new trial.

It was earlier suggested that the fridge was not a useful appliance for determining the person's wellbeing as it turns on and off automatically. However, this is not entirely true as on closer inspection (see Figure 2), it was found that the number of switching events actually decreased dramatically around times of high use on some days. This at first seems counter intuitive as you might expect that a fridge would need to turn on more often when the door is being opened. Nevertheless, the observation might be explained by the fact that the particular fridge being monitored is designed to not turn on when the fridge door is open. Therefore it might be possible to use this information to determine if the occupant is actually using the fridge - a useful sign of their wellbeing. It also suggests that a longer period of inactivity (say 5 hours) should be used to determine if an appliance is turning on automatically or not.

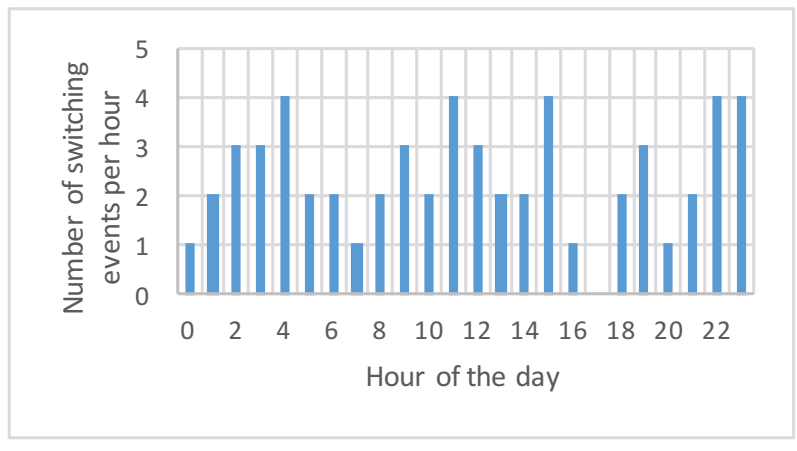

Figure 2. The frequency of switching (on and off) of a fridge on one particular day. It can be seen that the frequency changes throughout the day with a noticeable reduction at 5 p.m. (17) when the fridge door was being frequently opened

The smappee user interface allows users to manually label the individual appliances that it finds - otherwise they are just referred to by a number. However, it is possible that an analysis of the appliances characteristics (power and frequency of use) may identify some of these appliances with a reasonable accuracy, for example, the microwave oven or kettle. Machine learning techniques could be used to help with this identification process.

\section{Conclusions and summary}

The confluence of a number of technologies has enabled the creation of a low intrusive and low cost monitoring system to become a reality. The initial trial of a system based on an off-the-shelf NILM based electricity monitor has been shown to be a most reliable alternative to a system built on multiple sensors. Based on previous work that involved the deployment of multiple sensors, the new system is expected to be more acceptable as it has the desired attribute of becoming invisible to the user. 


\section{References}

Berges, M., Goldman, E., Matthews, S., Soibelman, L., \& Anderson, K. (2011). User-Centered Nonintrusive Electricity Load Monitoring for Residential Buildings. Journal of computing in civil engineering, 471-480.

Chahine, K., Khamlichi Drissi, K., Pasquier, C., Kerroum, K., Faure, C., Jouannet, T., \& Michou, M. (2011). Electric Load Disaggregation in Smart Metering Using a Novel. Energy Procedia, 627-632.

Chen, C. (2010). A Data Mining Framework for Activity Recognition in Smart Environments. Intelligent Environments (IE), 2010 Sixth International Conference on (pp. 80-83). Kuala Lumpur: IEEE.

Clement, J., Ploennigs, J., \& Kabitzsch, K. (2012). Smart Meter: Detect and Individualize ADLs. In R. Wichert, \& B. Eberhardt, Ambient Assisted Living (pp. 107-122). Heidelberg: Springer Berlin Heidelberg.

Cook, D. J., \& Holder, L. B. (2011). Sensor Selection to Support Practical Use of Health-Monitoring. Data Mining and Knowledge Discovery, 339-351.

Current cost (2015, 05 10). Save money and cut your electricity waste. Retrieved from http://currentcost.com/

Farinaccio, L., \& Zmeureanu, R. (1999). Using a pattern recognition approach to disaggregate the total electricity. Energy and Buildings, 245-259.

Google (2015, 05 10). App engine. Retrieved from Google cloud platform: https://cloud.google.com/appengine/

Hart, G. W. (1992). Nonintrusive Appliance Load Monitoring. Proceedings of the IEEE, 1870-1891.

Hunt, T. D., Rajendran, D., Bennett, S., \& Fendall, A. (2014). A minimally intrusive monitoring system that utilizes electricity consumption as a proxy. Journal of Applied Computing and Information Technology. Retrieved from http://www.citrenz.ac.nz/jacit/JACIT1802/2014Hunt_Monitoring.pdf

Lawton, M. P., \& Brody, E. M. (1969). Activities of Daily Living Evaluation. Self-maintenance, P, 179-186. Retrieved from http://www.eurohex.eu/bibliography/pdf/Lawton_Gerontol_1969-1502121986/Lawton Gerontol_1969.pdf

Monekosso, D. N., \& Remagnino, P. (2007). Monitoring behavior with an array of sensors. Computational intelligence, 420-438.

Navetas energy management (2015, 04 10). Connected energy. Retrieved from http://www.navetas.com/

Oracle (2015, 05 10). How can I get started developing Java programs with the Java Development Kit (JDK)? Retrieved from Java: http://java.com/en/download/faq/develop.xml

Peffers, K., Tuunanen, T., Rothenberger, M. A., \& Chatterjee, S. (2007). A design science research methodology for information systems research. Journal of Management Information Systems, 45-78.

smappee (2015, 04 10). Understand your energy use, see the cost and save. Retrieved from http://www. smappee.com/au/

The energy detective (2015, 05 10). The most comprehensive real-time electricity monitor on the planet. Retrieved from http://www.theenergydetective.com/home

Twilio (2015, 05 10). The Twilio Platform. Retrieved from Twilio: https://www.twilio.com/ 